\title{
Accessing the most lethal product on the market: community perceptions of tobacco accessibility in NSW, Australia
}

\author{
Christina Watts ${ }^{a, b, d}$, Anita Dessaix ${ }^{a}$, Alecia Brooksª, Suzan Burton and \\ Becky Freeman ${ }^{b}$ \\ a Cancer Prevention and Advocacy Division, Cancer Council NSW, Sydney, Australia \\ b Faculty of Medicine and Health, School of Public Health, Prevention Research Collaboration, University of Sydney, NSW, Australia \\ - School of Business, Western Sydney University, NSW, Australia \\ d Corresponding author: christina.watts@sydney.edu.au
}

\section{Article history}

Publication date: September 2020 Citation: Watts C, Dessaix A, Brooks A, Burton S, Freeman B. Accessing the most lethal product on the market: community perceptions of tobacco accessibility in NSW, Australia. Public Health Res Pract. 2020;30(3):e3032023. https://doi.org/10.17061/phrp3032023

\section{Abstract}

Aim: This study aims to describe the perceived ease of accessing tobacco retail outlets in New South Wales (NSW), Australia, and the sociodemographic factors associated with reported higher density of tobacco retail outlets.

Methods: A cross-sectional online survey was conducted with a sample of NSW adults in February 2019. The accessibility of cigarettes was assessed and a binary logistic regression model was used to examine characteristics associated with having four or more retailers within a 5-minute drive of their home.

Results: A total of 3213 NSW adults completed the survey. The vast majority of participants, $89.9 \%(n=2888)$, described cigarettes as being easily accessed from where they live. Half of the participants $(50.7 \%)$ reported having four or more tobacco retail outlets within a 5-minute drive of their home. Never-smokers were significantly less likely than daily smokers to report four or more tobacco retailers within a 5-minute drive of their home, although non-smokers may be less likely to identify tobacco retailers. Females, those living in regional areas of NSW and those with a university qualification were also less likely to report having four or more tobacco retailers within a 5-minute drive of their home.

Conclusion: The ease of access to tobacco retailers in NSW is incongruent with the significant health risks associated with tobacco use and highlights the need for measures to reduce the supply of tobacco, such as a fee-based tobacco licensing system.

\section{Introduction}

Tobacco smoking is the leading cause of preventable death and disease in New South Wales (NSW), Australia, yet tobacco products remain one of the most widely available consumer goods on the market. ${ }^{1}$ The widespread 
distribution of tobacco retailers contributes to increased tobacco consumption, smoking maintenance, and undermines smokers' quit attempts. ${ }^{2-4}$ In NSW, there are an estimated 10000 tobacco retail outlets, and without comprehensive tobacco supply-reduction policies, it appears that very few retailers stop selling tobacco. ${ }^{5}$ Access to tobacco retailers has been shown to be high in NSW, with previous research indicating that almost three-quarters (74.1\%) of current smokers in NSW reported living within walking distance of a tobacco retail outlet ${ }^{2}$, and a 2016 study finding an average of 17.7 tobacco retailers per NSW postcode. ${ }^{6}$ However, there have been no studies examining community perceptions of the retail accessibility of tobacco in NSW since 2010. ${ }^{2}$ This paper describes the perceived ease of accessing tobacco retailers in the NSW community, and the sociodemographic factors associated with reported higher density of tobacco retail outlets.

\section{Methods}

The Cancer Prevention Community Survey is a threeyearly online survey designed to measure community attitudes and behaviours on a range of cancer-related topics, including tobacco. The sampling methodology of an earlier (2016) version of the survey is described in detail elsewhere. ${ }^{7}$ The data discussed in this paper was collected in a survey conducted between 31 January and 22 February 2019 with a panel of adult (18 years or older) residents of NSW. Survey respondents were sourced via the Online Research Unit online panel (a non-probability access panel). ${ }^{8}$ The final survey sample was weighted to be representative of the full NSW adult population. Quotas were set for age, gender, highest level of education and region, with weighting targets derived from Australian Bureau of Statistics population estimates. ${ }^{9}$ Weights were calculated for each respondent and included in the final dataset.

This paper reports on data relating to the accessibility of tobacco retailers only. All survey participants were asked two questions assessing their perceptions of their ease of access to cigarette retail outlets:

1. "Thinking about the neighbourhood where you live, how easy or hard is it to find a shop selling cigarettes?" The response options were: 'very easy', 'easy', 'somewhat easy', 'neither easy nor hard', 'somewhat hard', 'hard', and 'very hard'

2. "Within a five-minute drive from where you live, how many places do you think there are that sell cigarettes?" The scaled response options were: 'none', 'one', 'two to three', 'four to six', 'seven to nine', and '10 or more'.

\section{Data analysis}

Percentages were calculated for the perceived ease of access to cigarette retailers and a binary logistic regression model was used to examine characteristics associated with having four or more retailers within a 5-minute drive of place of residence. The scaled response options were divided into two groups, with low/ medium density defined as zero to three retailers and high density defined as four or more. A similar criterion has been used in another study, which considered five or more tobacco retailers to be high density. ${ }^{10}$

The variables included in the binary logistic regression models were smoking status, gender, age, location ('Sydney and suburbs' or 'other NSW'), education (university qualification or not) and the Socio-Economic Indexes for Australia (SEIFA) quintiles for NSW. ${ }^{11}$ Adjusted odds ratios with 95\% confidence intervals and $p$ values were calculated for variables within the model.

\section{Results}

The survey was sent to 63000 panellists via direct email invitation, of which 5767 (9.2\%) clicked on the survey link, and $3213(5.1 \%)$ completed the survey.

A large majority of participants reported being able to easily access cigarette outlets in the neighbourhoods where they live, with $59.6 \%(n=1915)$ of participants reporting that a shop selling cigarettes was very easy to access, $20.4 \%$ ( $n=657)$ reporting cigarette outlets as easy to access and $9.8 \%(n=316)$ reporting cigarette outlets as somewhat easy to access. Only $2.6 \%$ $(n=82)$ of participants reported cigarette outlets as being somewhat hard, hard or very hard to access in their neighbourhood. A further $7.6 \%(n=243)$ said that cigarette outlets were neither easy nor hard to access.

Table 1 shows the logistic regression analyses of reporting having four or more tobacco retailers within a 5-minute drive of place of residence. Half of the participants $(50.7 \%)$ reported having four or more tobacco retail outlets within a 5-minute drive of their home. Never-smokers were significantly less likely than daily smokers to report four or more tobacco retailers within a 5-minute drive of their home (Odds Ratio [OR] 0.77, 95\% Confidence Interval [Cl] 0.60, 0.99). Participants living in regional areas of NSW were also significantly less likely to report having four or more tobacco retailers within a 5-minute drive of their home (OR 0.61, 95\% Cl 0.51, 0.73). Participants with a university degree were also significantly less likely to report four or more tobacco retailers within a 5-minute drive of their home (OR 0.79, 95\% Cl 0.67, 0.94). After allowing for all other variables (which included education) there was no difference in the reported density of tobacco retailers within a 5-minute drive (more than 3) according to SEIFA level. Female participants were significantly less likely than males to report four or more tobacco retailers within a 5-minute drive (OR 0.74, 95\% Cl 0.64, 0.86). 
Table 1. Characteristics associated with having a high density of tobacco retailers (four or more) within a 5-minute drive

\begin{tabular}{lcc}
\hline & & Odds ratio for $\geq 4$ (vs $0-3)$ \\
\cline { 2 - 2 } Characteristic & Respondents with $\geq 4$ retailers/all \\
respondents $n / N(\%)$ & $\begin{array}{c}\text { Adjusted OR } \\
(95 \% \mathrm{Cl})\end{array}$ \\
$\begin{array}{l}\text { All respondents with } \geq 4 \text { retailers within } \\
\text { 5-minute drive }\end{array}$ & $1546 / 3048(\mathbf{5 0 . 7})$ & $p$ value \\
\hline
\end{tabular}

Smoking status

Daily smoker

166/307 (54.1)

ref

ref

Occasional smoker

72/142 (50.7)

$0.76(0.52,1.16)$

0.22

Former smoker

418/758 (55.1)

$1.09(0.83,1.44)$

0.67

Tried smoking

199/358 (55.6)

$1.04(0.76,1.43)$

0.79

Never smoker

691/1483 (46.6)

$0.77(0.60,0.99)$

0.04

\section{Gendera $^{a}$}

Male

$815 / 1485$ (54.9)

ref

ref

Female

$728 / 1559$ (46.7)

$\begin{array}{cc}0.74(0.64,0.86) & <0.001 \\ 1.00(0.99,1.00) & 0.12\end{array}$

Age (continuous variable)

$1.00(0.99,1.00)$

0.12

Location

Sydney and suburbs

$1133 / 2089(54.2)$

ref

ref

Other NSW

$413 / 959(43.1)$

$0.61(0.51,0.73)$

$<0.001$

\section{Education}

No university degree

1053/2041 (51.6)

ref

ref

University qualification

493/1007 (49.0)

$0.79(0.67,0.94)$

0.008

SEIFA Quintile ${ }^{b}$

1 (Most disadvantaged)

201/396 (50.8)

ref

ref

2

261/557 (46.9)

$0.88(0.68,1.14)$

0.34

3

309/622 (49.7)

$0.95(0.74,1.23)$

0.71

4

243/470 (51.7)

$0.89(0.67,1.17)$

0.41

5 (Least disadvantaged)

527/994 (53.0)

$0.89(0.69,1.14)$

0.34

$\mathrm{Cl}$ = Confidence Interval; OR = Odds Ratio; NSW = New South Wales; ref = reference category; SEIFA = Socio-Economic Indexes for Australia.

a For the purpose of the model, gender was male or female only.

b SEIFA quintiles could not be calculated for nine invalid postcodes.

Note: 'Don't know' and 'unsure' responses were excluded from the model.

\section{Discussion and implications}

The perceived ease of access to tobacco retailers in NSW is incongruent with the significant health risks associated with the use of tobacco. The vast majority of participants (89.9\%) described cigarettes as being easily accessed from where they live, and daily smokers were more likely than never-smokers to report a higher density of tobacco retailers within 5-minutes' drive from where they live. Given that the widespread availability of tobacco increases tobacco consumption and impulse purchases among smokers (making it harder for smokers to quit) ${ }^{2-4}$, these findings give further evidence of the need for measures to reduce the supply of tobacco in NSW.

Unlike the majority of Australian states and territories (South Australia, Tasmania, Western Australia, Australian Capital Territory and Northern Territory), NSW has not adopted a fee-based tobacco retailer licensing scheme. In South Australia, a 15-fold increase in the annual cost of the tobacco licence fee introduced in 2007 resulted in a $23.7 \%$ decrease in the number of tobacco retailers in the following 2 years. ${ }^{12}$ Some retailers in Western Australia that stopped selling tobacco products cited the feebased tobacco licence as a key factor in their decision. ${ }^{5}$ 
Curbing the retail availability of tobacco through such supply-reduction measures is a critical next step for NSW to continue to support current smokers to quit and reduce smoking prevalence across the community.

\section{Study limitations}

Data from this study is cross-sectional and therefore we cannot demonstrate that a higher density of tobacco outlets increases tobacco consumption. Although the results were weighted according to NSW population levels, there is also a possibility that sampling biases were present since only $5 \%$ of the panellists invited to participate completed the survey. When interpreting the results, it should be noted that it is likely that never smokers are less aware of the location of tobacco retail outlets in their local area than smokers, which could result in never smokers under-reporting the number of tobacco retailers within a 5-minute drive of their home. However, any effect due to non-smokers being unaware of some tobacco retailers would mean that our estimates of the number of tobacco retailers are an underestimate, indicating that the problem of tobacco retailer accessibility is even greater than reported.

\section{Acknowledgements}

The study was funded by a Cancer Council NSW grant for the 2019 NSW Cancer Prevention Survey. The authors thank Cancer Council NSW for funding the study, Sally Dunlop for assistance with the development of the survey questions, the Social Research Centre for administering the online survey, the community members for participating in the online survey and Rhiannon Davies for assistance with data analysis.

\section{Peer review and provenance}

Externally peer reviewed, not commissioned.

\section{Competing interests}

None declared.

\section{Author contributions}

CW, AD, AB and BF contributed to the study design and survey development. CW analysed and interpreted the data, and wrote the first draft of the manuscript. SB and BF contributed to the interpretation of the data. All authors reviewed, contributed to and approved the final manuscript.

\section{Copyright: (c) ()요 (2)}

(C) 2020 Watts et al. This article is licensed under the Creative Commons Attribution-NonCommercial-ShareAlike 4.0 International Licence, which allows others to redistribute, adapt and share this work non-commercially provided they attribute the work and any adapted version of it is distributed under the same Creative Commons licence terms. See: www.creativecommons.org/licenses/by-nc-sa/4.0/

\section{References}

1. Intergovernmental Committee on Drugs. National tobacco strategy 2012-2018. Canberra: Commonwealth of Australia; 2012 [cited 2020 Aug 4]. Available from: www1.health.gov.au/internet/main/publishing.nsf/Content/ national_ts_2012_2018

2. Paul CL, Mee KJ, Judd TM, Walsh RA, Tang A, Penman A, et al. Anywhere, anytime: retail access to tobacco in New South Wales and its potential impact on consumption and quitting. Soc Sci Med. 2010;71(4):799-806.

3. Burton S, Clark L, Jackson K. The association between seeing retail displays of tobacco and tobacco smoking and purchase: findings from a diary-style survey. Addiction. 2012;107(1):169-75.

4. Burton S, Hoek J, Nesbit P, Khan A. "Smoking is bad, it's not cool... yet l'm still doing it": cues for tobacco consumption in a 'dark' market. Journal of Business Research. 2015;68(10):2067-74.

5. Watts C, Burton S, Phillips F, Kennington K, Scollo M, Lindorff K, et al. Understanding why some Australian retailers have stopped selling tobacco, some might and some are unlikely. Tob Control. 2019:tobaccocontrol-2019-055142.

6. Fry R, Burton S, Williams K, Walsberger S, Tang A, Chapman K, et al. Retailer licensing and tobacco display compliance: are some retailers more likely to flout regulations? Tob Control. 2017;26:181-7.

7. Twyman L, Watts C, Chapman K, Walsberger SC. Electronic cigarette use in New South Wales, Australia: reasons for use, place of purchase and use in enclosed and outdoor places. Aust N Z J Public Health. 2018;42(5):491-6.

8. THEORU. Online research unit. Sydney: THEORU; 2014 [cited 2020 Aug 6]. Available from: www.theoru.com/index.htm

9. Australian Bureau of Statistics. Australian demographic statistics, Jun 2018. Canberra: ABS; 2018 [cited 2020 Jan 17]. Available from: www.abs.gov.au/AUSSTATS/abs@. nsf/allprimarymainfeatures/E18EA7BE5701F459CA2583C 3000C53C8?opendocument

10. Henriksen L, Feighery EC, Schleicher NC, Cowling DW, Kline RS, Fortmann SP. Is adolescent smoking related to the density and proximity of tobacco outlets and retail cigarette advertising near schools? Prev Med. 2008;47(2):210-4.

11. Australian Bureau of Statistics. Socio-economic indexes for areas. Canberra: ABS; 2018 [cited 2020 Aug 6]. Available from: www.abs.gov.au/websitedbs/ censushome.nst/home/seifa

12. Bowden JA, Dono J, John DL, Miller CL. What happens when the price of a tobacco retailer licence increases? Tob Control. 2014;23(2):178-80. 